\title{
PERDAS DE ÁGUA E SEDIMENTO EM DIFERENTES SISTEMAS DE MANEJO NO SEMIÁRIDO DA PARAÍBA
}

\author{
Water and Soil Losses in Different Management Systems in Semiarid Region of Paraíba \\ Richarde Marques da Silva* \\ Celso Augusto Guimarães Santos** \\ Vajapeyam Srirangachar Srinivasan***
}

\begin{abstract}
Resumo
O presente trabalho busca descrever as perdas de água e sedimentos na Bacia Experimental de São João do Cariri - BESJC. A BESJC está nas coordenadas $-7^{\circ} 22^{\prime}$ de latitude e $-36^{\circ} 31^{\prime}$ 'de longitude, no semiárido do Estado da Paraíba, Brasil. Os dados de perda de água e sedimento foram obtidos em duas parcelas de erosão de $100 \mathrm{~m}^{2}$ com sistema de manejo e cobertura superficial do solo diferenciada, sendo uma parcela mantida desmatada (1999-2006) e outra com vegetação rasteira nativa (caatinga), em um período de três anos (1999-2002) e depois mantida desmatada (2003-2006). As perdas de solo para a parcela com caatinga foram bem abaixo dos valores obtidos na parcela desmatada, indicando a adequação do manejo deste sistema de produção em relação à erosão hídrica. Os resultados de erosão, obtidos na BESJC, mostram que a erosão média na Parcela 1 foi $3,4 \mathrm{t} \mathrm{ha}^{-1}$, enquanto que na Parcela 2 foi de $0,4 \mathrm{t} \mathrm{ha}^{-1}$, mostrando a influência da cobertura vegetal sobre o processo erosivo no semiárido.
\end{abstract}

Palavras-chave: Cobertura vegetal, perda de água, erosão, semiárido.

\begin{abstract}
This study sought to describe the water and sediment losses under various types of cover-management in the São João do Cariri Experimental Basin - BESJC, located in the coordinates $-7^{\circ} 22^{\prime}$ latitude and $-36^{\circ}$ 31 ' longitude, within the semiarid region of Paraíba State, Brazil. The runoff and sediment yield data were collected in two erosion plots of $100 \mathrm{~m}^{2}$ with different surface covers: one with bare soil (1999-2006) and another with common grass cover during three years (1999-2002) but later it was maintained with cleared bare soil (2003-2006). The values of soil losses in the common grass covered plot were smaller than the ones obtained in the bare soil plot, which indicates the adequacy of management in this production system, regarding the water erosion. The erosion results, obtained in the BESJC, showed that erosion in the Plot 1 was $3.4 \mathrm{t} \mathrm{ha}^{-1}$, while in the Plot 2 was $0.4 \mathrm{t} \mathrm{ha}^{-1}$, which shows the influence of the vegetation cover on the erosion process in semiarid lands.
\end{abstract}

Key words: Vegetal cover, water loss, erosion, semiarid region.

\section{Resumen}

El presente trabajo busca describir las pérdidas de agua y sedimentos en la Cuenca Experimental de São João do Cariri-BESJC. La BESJC está ubicada en las coordenadas $-7^{\circ} 22^{\prime}$ de latitud y $-36^{\circ} 31^{\prime}$ de longitud, en la región semiárida del estado de Paraíba, Brasil. Los datos de pérdida de agua y sedimento fueron obtenidos en dos parcelas de erosión de $100 \mathrm{~m}^{2}$ con el sistema de gestión y mantillo diferenciada, siendo una parcela mantiene despejado (1999-2006) y otra con baja vegetación nativa (Caatinga), en un período de tres años (1999-2002) y después mantenida despejada (2003-2006). Las pérdidas de suelo de la parcela con Caatinga fueron muy inferiores a los valores obtenidos en la parcela despejada, lo que indica la adecuación de la gestión en este sistema de producción en relación con la erosión. Los resultados de erosión, obtenidos en la BESJC, muestran que la erosión media en la Parcela 1 fue 3,4 tha ${ }^{-1}$, mientras que en la Parcela 2 fue de 0,4 t ha ${ }^{-1}$, lo que demuestra la influencia de la vegetación sobre la erosión en las zonas semiáridas.

Palabras clave: Vegetación, pérdida de agua, erosión, región semiárida.

(*) Prof. Dr. do Departamento de Geociências da Universidade Federal da Paraiba - Centro de Ciências Exatas e da Natureza, CEP 58.051-900, João Pessoa (PB) - Brasil, Tel.: (+ 55 83) 3043-3170 - richarde@geociencias.ufpb.br

(**) Prof. Dr. do Departamento de Engenharia Civil e Ambiental, CEP: 58.051-900 - Joao Pessoa (PB) - Brasil, Tel/Fax: (+55 83) 32167684 / 32167684 - celso@ct.ufpb.br

$(* * *)$ Prof. Dr. do Nucleo de Tecnologia da Universidade Federal de Pernambuco - Rodovia BR 104, KM 59, s/n, Sítio Juriti, Zona Rural, CEP: 55.002-970 - Caruaru (PE) - Brasil, Tel: (+55 81)2126 7774 - vajapeyam@yahoo.com 


\section{INTRODUÇÃO}

A erosão hídrica do solo é um processo natural influenciado pela chuva, tipos de solo, declividade, cobertura e manejo do solo e práticas conservacionistas. Dentre esses fatores, a cobertura e o manejo do solo apresentam maior influência sobre a erosão hídrica do que os demais (GUADAGNIN et al., 2005). A erosão dos solos é entendida como o desprendimento, o transporte e a deposição das partículas de sedimentos, resultante dos processos controladores da erosão, das condições dos solos e do manejo da cobertura superficial do solo (FREITAS et al., 2008). A erosão dos solos é extremamente variável temporal e espacialmente, e essa variabilidade deve-se ao fato das diferenças nas condições da superfície, ou seja, das características do solo e das condicionantes climáticas da região, que afetam diretamente o escoamento superficial.

Sobre a influência da cobertura vegetal nos processos de erosão, Brandt (1986), ressalta que o tipo de vegetação pode atuar de duas maneiras: (a) reduzindo o volume de água que chega ao solo, através da interceptação, e (b) alterando a distribuição do tamanho das gotas de chuva, afetando, com isso, a energia cinética da chuva.

Nas regiões semiáridas, como é o caso de grande parte do Estado da Paraíba, a erosão dos solos é um sério problema, e por isso vem sendo estudada nas últimas décadas por pesquisadores de órgãos que se preocupam com os aspectos físicos do solo, questões ambientais e suas relações socioeconômicas para a população local (ALBUQUERQUE et al., 2005; SOUZA et al., 2009; SOUZA et al., 2010). A região semiárida da Paraíba compreende uma vasta área na região Nordeste do Brasil, e caracteriza-se do ponto de vista geoambiental, pela diversidade de suas paisagens, tendo como elemento marcante, no quadro natural da região, a condição de semiaridez que atinge grande parte do seu território e a alta variabilidade pluviométrica espacial e temporal inerente ao semiárido (SALES, 2004).

Diante da importância de se estudar as perdas de água e do solo na região semiárida do Nordeste, diversos estudos vêm sendo realizados nas últimas décadas. Santos et al. (2000) analisaram a influência da cobertura vegetal sobre a erosão na Bacia Experimental de Sumé utilizando uma equação empírica e compararam os valores de lâmina escoada e produção de sedimentos calculados pela equação e os dados observados em várias parcelas de erosão, as quais apresentavam condições de cobertura vegetal e declividade distintas.

Albuquerque et al. (2002) estudaram os efeitos do manejo e da cobertura do solo sobre as perdas de solo e água provocadas por chuvas erosivas, em um solo Luvissolo Crômico Vértico, na Bacia Experimental de Sumé, Paraíba. Na parcela desmatada em alqueive contínuo contribuiu com perdas anuais de solo e água de $23,1 \mathrm{t} \mathrm{ha}^{-1}$ e $201 \mathrm{~mm}$, respectivamente. Nas parcelas desmatadas as perdas de solo e água foram de 35,7 e $58,5 \mathrm{t} \mathrm{ha}^{-1}$ e 224,2 e $241,0 \mathrm{~mm}$, respectivamente, enquanto a parcela com caatinga nativa e quando comparada com a parcela desmatada, teve uma redução na perda de solo em aproximadamente $99 \%$ e na perda de água em torno de $89 \%$; já nas parcelas com cobertura morta houve redução de aproximadamente $99 \%$ das perdas de solo e $74 \%$ das perdas de água em relação às parcelas desmatadas. A palma cultivada em nível reduziu as perdas de solo em $53,4 \%$, quando comparada àquela cultivada morro abaixo.

Silva et al. (1999) analisaram o efeito de diferentes graus de mobilização sobre as perdas de solo e água na produtividade de milho (Zea mays L.) e feijão (Phaseolus vulgaris L.), em condições de chuva natural em um Regossolo eutrófico, com 12\% de declividade no município de Caruaru, Estado de Pernambuco. Observaram que a tolerância às perdas por erosão variaram entre $2 \mathrm{e} 4$ t ha $^{-1}$ $\mathrm{ano}^{-1}$, e que esses valores são admissíveis para regiões com subsolo desfavorável e pouco profundo.

Santos et al. (2009) analisaram as propriedades hidráulicas e perdas de solo e água sob cultivo do feijoeiro na Bacia Experimental do Jatobá, localizada no município de Pesqueira, Pernambuco. $\mathrm{O}$ estudo foi realizado em 18 parcelas experimentais com dimensões de $3 \mathrm{~m}$ de comprimento por $1 \mathrm{~m}$ de largura. Concluíram que houve uma redução de 99,2\% entre os valores médios de perda de solo nas parcelas com cobertura nativa e desmatada, semelhante ao encontrado por Albuquerque et al. (2002), para essas mesmas condições de cobertura do solo, na região de Sumé, Paraíba. 
Entre os principais problemas enfrentados para a realização de estudos de perda de água e sedimento, estão: (a) dificuldades de monitoramento da variabilidade espacial da precipitação, escoamento e erosão, (b) custos financeiros na coleta de dados hidroclimatológicos em campo, (c) falta de recursos humanos na coleta e tratamento dos dados, e (d) calibração de modelos matemáticos empíricos ou de base física para a predição de erosão e escoamento superficial para as bacias da região semiárida.

No que tange a falta de dados sobre as características físico-hidráulicas dos solos do semiárido nordestino, Santos et al. (2003) apresentaram técnica para calibração automática de parâmetros físicos dos solos utilizando algoritmo genético implantado no modelo computacional WESP. Santos et al. (2005) aplicaram o mesmo procedimento para determinar parâmetros físicos do solo utilizando dados observados de erosão obtidos em parcelas instaladas em Sumé e São João do Cariri, região semiárida da Paraíba.

Como alternativas para suprir os problemas da obtenção de dados e análise de dados, foram implantadas bacias experimentais em diversos locais da região Nordeste, para aquisição de dados hidrológicos, como é o caso da Bacia Experimental de São João do Cariri - BESJC. Na BESJC são obtidas informações de perdas de água e solo em escala de parcela microbacia e sub-bacia, permitindo a realização de estudos sobre o comportamento da erosão dos solos no semiárido paraibano.

A realização de estudos envolvendo perdas de água e solo na região semiárida é de suma importância para o desenvolvimento local da região. Ainda são poucos os estudos de erosão dos solos sob a caatinga, e a influência desse tipo de cobertura superficial ainda não está totalmente esclarecido (CANTALICE et al., 2008; MELO et al., 2008). Outro importante fator que motiva a realização de estudos sobre erosão no semiárido é que a vegetação do tipo caatinga cobre uma grande área do semiárido nordestino e, ocorre em todos os estados da região Nordeste abrangendo uma área de aproximadamente $750.000 \mathrm{~km}^{2}(11 \%$ do território brasileiro e $54 \%$ do território nordestino), englobando partes dos territórios dos Estados da Região Nordeste e parte de Minas Gerais (ALVES et al., 2009).

Segundo Freitas et al. (2008) a capacidade da caatinga de suportar os impactos provocados pela chuva e o escoamento superficial, na forma de erosão hídrica, é pouco conhecida. Além disso, centenas de milhares de hectares de vegetação do tipo caatinga são derrubadas anualmente para produção de lenha e para plantio no sistema de agricultura itinerante (SAMPAIO et al., 1998).

Diante disso, a quantificação da erosão hídrica com o conhecimento dos processos físicos a ela atrelados é de fundamental importância na elaboração de medidas que visam maximizar o uso dos recursos hídricos disponíveis e para evitar os efeitos negativos decorrentes da erosão dos solos na região semiárida. Assim, este trabalho analisou as perdas de solo e água em um Luvissolo Crômico sob diferentes sistemas de manejo e coberturas do solo.

\section{MATERIAL E MÉTODOS}

\section{A área de estudo e experimentos}

A Bacia Experimental de São João do Cariri - BESJC, possui uma área de aproximadamente $15 \mathrm{~km}^{2}$, inserida entre as coordenadas $7^{\circ} 20^{\prime} 12^{\prime \prime}$ e $7^{\circ} 23^{\prime} 17^{\prime \prime}$ de latitude Sul e $36^{\circ} 31^{\prime} 22^{\prime \prime}$ e $36^{\circ}$ 32' 58" de longitude Oeste. A BESJC foi instalada em 1997 e conta atualmente com o apoio de diversos órgãos financiadores, como: FINEP, CT-HIDRO e CNPq, através de projetos, como por exemplo, o IBESA (Implantação de Bacias Experimentais no Semi-árido) e o BEER-UFCG (Bacias Experimental e Representativa da Rede de Hidrologia do Semi-Árido), que apoiam a continuidade das atividades de pesquisas sobre escoamento superficial e erosão dos solos na bacia.

Segundo a classificação climática de Köeppen, o clima enquadra-se no tipo BSh, denominado semiárido, caracterizado por insuficiência e irregularidade das precipitações pluviais e ocorrência 
de temperaturas elevadas. A precipitação pluvial média anual, observada no período de 1986 a 1990, foi de $565 \mathrm{~mm}$, a temperatura média anual é de $24^{\circ} \mathrm{C}$ e a umidade relativa média anual é de aproximadamente 57\% (SANTOS et al., 2007).

A BESJC é constituída por solos rasos, pouco porosos e predominantemente plásticos, subsolo derivado do embasamento cristalino, vegetação do tipo caatinga e relevo bastante ondulado, com altitudes variando entre 450 a $700 \mathrm{~m}$. Os principais tipos de solos encontrados na região são: Luvissolo Crômico Vértico, Vertissolo e Neossolo Lítico, com horizonte A fraco e textura argilosa fase caatinga hiperxerófila.

A avaliação da influência dos diferentes sistemas de manejo do solo nas perdas de água e sedimento foi realizada comparando-se os dados observados de lâmina escoada e de erosão produzidos em duas parcelas de $100 \mathrm{~m}^{2}$ (4,5 - 22,2 m). As parcelas de erosão foram mantidas sob condições distintas no que tange à cobertura do solo. Uma descrição mais detalhada das características das parcelas é apresentada na Tabela 1. As Figuras 2A e 2B mostram respectivamente a Parcela 1 (desmatada) e os detalhes dos tanques coletores de sedimentos e de lâmina escoada das parcelas de erosão. Após cada evento de chuva as amostras da enxurrada são retiradas dos tanques coletores das parcelas para a determinação das perdas de solo e água, de acordo com as recomendações de Cadier et al. (1983).

Tabela 1 - Característica das parcelas da Bacia Experimental de São João do Cariri

\begin{tabular}{c|c|l|c}
\hline PARCELA & $\begin{array}{c}\text { Declividade média } \\
(\mathbf{\%})\end{array}$ & \multicolumn{1}{|c|}{ Sistema de Manejo/Cobertura do Solo } & Período de dados \\
\hline 1 & 3,4 & Desmatada & $1999-2006$ \\
\hline \multirow{2}{*}{2} & 3,6 & Vegetação rasteira com cobertura morta & $1999-2002$ \\
\cline { 2 - 3 } & & Desmatada & $2003-2006$ \\
\hline
\end{tabular}

$\mathrm{Na}$ BESJC existem ainda três microbacias e quatro sub-bacias instrumentadas. Neste estudo foram utilizados dados de produção de sedimentos e de escoamento registrados no exutório da microbacia 1, com área de 0,18 ha. Os dados de erosão e escoamento são utilizados para análise dos processos hidrossedimentológicos em escala de microbacia e são extrapolados para outras bacias da região semiárida. Essa microbacia foi escolhida, devido ao fato de possuir grande número de eventos hidrológicos observados.
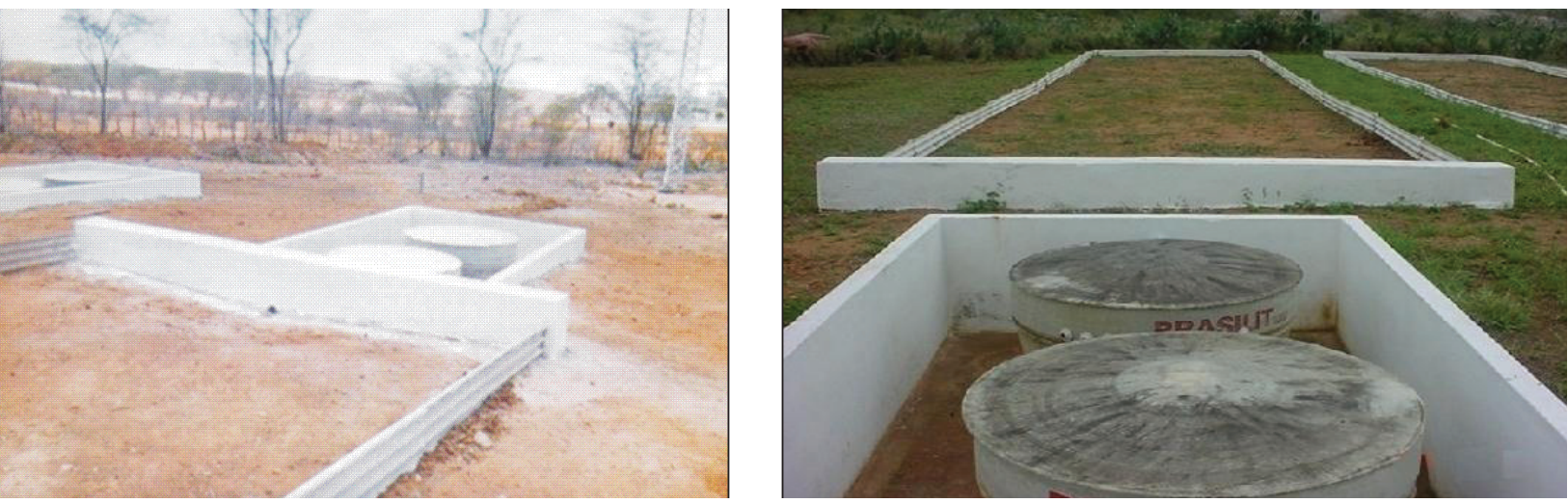

Figura 1 - Parcelas de erosão na Bacia Experimental de São João do Cariri: (A) Vista da Parcela 1 (desmatada), e (B) Detalhe dos tanques para coleta de dados.

Os dados observados de chuva, lâmina escoada e erosão, aqui apresentados, fazem parte do acervo de dados coletados na BESJC, para as escalas de parcelas e de microbacia. Foram utilizados neste estudo 172 eventos de precipitação, lâmina escoada e erosão, coletados entre 1999 e 2006. Os dados de precipitação foram obtidos em um pluviógrafo localizado na bacia e os dados de lâmina escoada e erosão coletados no exutório da microbacia. 


\section{RESULTADOS E DISCUSSÃO}

\section{Influência da cobertura do solo nos processos hidrossedimentológicos nas parcelas}

Na Tabela 2 encontram-se os valores anuais e médios de precipitação e das perdas de água para as parcelas na BESJC, obtidos em diferentes sistemas de manejo e cobertura superficial, em um solo do tipo Luvissolo Crômico. A partir dos dados observados de lâmina escoada na BESJC, nota-se que a Parcela 1 (desmatada) obteve uma lâmina escoada anual média igual a 173,9 mm, enquanto que na Parcela 2 (mantida um tempo com vegetação rasteira com cobertura morta e outro período desmatada) foi observada uma média anual de $125,5 \mathrm{~mm}$, uma redução da perda de água igual a $27,87 \% \mathrm{~mm}$ (Tabela 2).

Tabela 2 - Precipitação total anual e perdas de água nas parcelas em São João do Cariri

\begin{tabular}{c|c|r|r|r|r|r}
\hline \multirow{2}{*}{ ANO } & \multirow{2}{*}{$\begin{array}{c}\text { Precipitação } \\
(\mathbf{m m})\end{array}$} & Parcela 1 & $\mathbf{\%}$ & Parcela 2 & \% & Redução (\%) \\
\cline { 3 - 7 } & 143 & 21,1 & 14,8 & 15,5 & 10,8 & 26,38 \\
\hline 1999 & 762 & 273,8 & 35,9 & 133,3 & 17,5 & 51,30 \\
\hline 2000 & 343 & 137,0 & 39,9 & 14,1 & 4,1 & 89,74 \\
\hline 2001 & 550 & 233,7 & 42,5 & 182,0 & 33,1 & 22,13 \\
\hline 2002 & 261 & 63,0 & 24,1 & 56,8 & 21,8 & 9,88 \\
\hline 2003 & 645 & 220,0 & 34,1 & 199,5 & 30,9 & 9,32 \\
\hline 2004 & 580 & 276,8 & 47,7 & 247,8 & 42,7 & 10,46 \\
\hline 2005 & 365 & 165,9 & 45,5 & 154,6 & 42,4 & 6,83 \\
\hline 2006 & $\mathbf{4 5 6}$ & $\mathbf{1 7 3 , 9}$ & $\mathbf{3 8 , 1}$ & $\mathbf{1 2 5 , 5}$ & $\mathbf{2 7 , 5}$ & $\mathbf{2 7 , 8 7}$ \\
\hline Média & & & &
\end{tabular}

Ainda de acordo com a Tabela 2, as perdas de água anuais totais apresentaram uma variação de 21,1 a 276,8 mm, para as condições de solo descoberto (Parcela 1) e 14,1 a 247,8 mm, para a parcela com cobertura vegetal nativa (Parcela 2). As menores perdas de água foram observadas para o sistema com cobertura vegetal nativa (caatinga), o que pode ser explicado pelo fato da interceptação das gotas de chuvas pelo dossel da vegetação, que mesmo não possuindo um extrato vertical muito diversificado, protege o solo.

Os menores valores de perda de água pela caatinga justificam-se pela maior resistência físico-hidráulica ao escoamento criada pela sua copa e camada de serrapilheira, traduzida no maior valor do coeficiente de rugosidade hidráulica. Pode-se afirmar que cobertura do tipo caatinga funcionou como barreira ao livre escoamento, permitindo que a enxurrada permanecesse mais tempo sob o solo, resultando em uma infiltração maior. Esses resultados concordam com os encontrados por Santos et al. (2009), para a condição de plantio direto, e por Albuquerque et al. (2002), para as condições de campo nativo e desmatado.

Esses resultados ressaltam o importante papel que a cobertura vegetal pode desempenhar no controle das perdas de água por escoamento superficial, principalmente, quando considerada a irregularidade temporal e espacial das chuvas na região semiárida no Nordeste do Brasil. Comparando-se apenas o período em que as duas parcelas detinham sistemas de manejo e cobertura do solo distinta (1999-2002), percebe-se uma diferença considerável nos valores observados, com redução variando de 22,13 a 89,74\%. A partir de 2002, com a retirada da vegetação rasteira, percebe-se o aumentou do gradual do escoamento.

Considerando todo o período de dados existentes, as perdas de água registradas na Parcela 1 , em relação à precipitação média anual $(456 \mathrm{~mm})$, foi de $38,1 \%$, enquanto que na Parcela 2 foi de $27,5 \%$, mostrando que estas áreas apresentaram valores considerados próximos, uma vez que, o tipo de manejo, em boa parte do tempo, foi igual em ambas as parcelas. Esses valores podem ser explicados, em parte, pelo fato de que as condições em ambas as parcelas eram semelhantes e, com o crescimento da cobertura vegetal, houve a diminuição do escoamento. 
As Figuras 2A e 2B mostram a representação gráfica de todos os eventos de perda de água registrados nas duas parcelas da BESJC. Nota-se que os eventos extremos de lâmina escoada foram semelhantes em ambas as parcelas, com exceção dos picos em alguns eventos isolados. Percebe-se também uma pequena diferença em relação aos valores das médias observadas, 7,56 mm na Parcela 1 e $5,45 \mathrm{~mm}$ na Parcela 2.
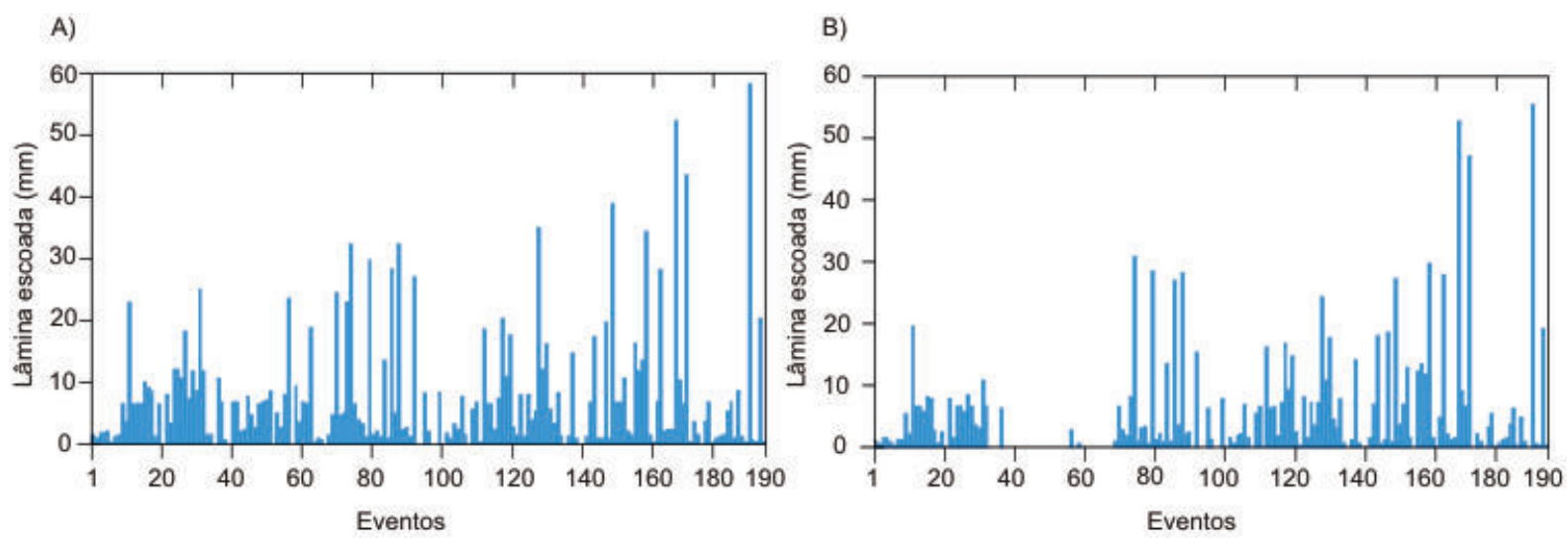

Figura 2 - Lâmina escoada nas parcelas de São João do Cariri: (A) Parcela 1, e (B) Parcela 2.

No que tange à comparação dos dados de erosão nas parcelas, observou-se que o valor médio anual de erosão na Parcela 1 (desmatada) em relação ao valor médio da Parcela 2 (mantida um tempo com vegetação rasteira, com cobertura morta e outro período desmatada), no período estudado, foi aproximadamente oito vezes maior, apresentando valores médios de erosão de 4,2 e 1,0 t ha-1, respectivamente, com uma redução de perdas de solo da ordem de 74,6\% (Tabela 3).

Tabela 3 - Precipitação total anual e perdas de solo nas parcelas em São João do Cariri

\begin{tabular}{c|c|c|c|c}
\hline \multirow{2}{*}{ ANO } & \multirow{2}{*}{$\begin{array}{c}\text { Chuva } \\
(\mathbf{m m})\end{array}$} & Parcela 1 & Erosão (t hä $\left.{ }^{-1}\right)$ & Parcela 2 $^{*}$ \\
\cline { 3 - 5 } & 143 & 1,2 & 0,3 & 75,0 \\
\hline 1999 & 762 & 14,4 & 1,5 & 89,6 \\
\hline 2000 & 343 & 4,1 & 0,1 & 97,6 \\
\hline 2001 & 550 & 3,2 & 0,5 & 84,4 \\
\hline 2002 & 261 & 1,1 & 0,1 & 90,9 \\
\hline 2003 & 645 & 2,9 & 0,6 & 79,3 \\
\hline 2004 & 580 & 4,6 & 3,3 & 28,3 \\
\hline 2005 & 365 & 2,3 & 2,2 & 4,3 \\
\hline 2006 & $\mathbf{4 5 6}$ & $\mathbf{4 , 2}$ & $\mathbf{1 , 0}$ & $\mathbf{7 4 , 6}$ \\
\hline
\end{tabular}

Na Parcela 1, os valores observados de erosão variaram entre 1,1 e 14,4 t ha ${ }^{-1}$, enquanto que, na Parcela 2, os valores observados são da ordem de 0,1 a 3,3 tha- ${ }^{1}$, ou seja, valores menores quando comparados com a Parcela 1. Isto mostra que existe influência direta da cobertura vegetal sobre as perdas de solo e água. A representação gráfica de todos os eventos registrados nas duas parcelas da BESJC mostra que os eventos mais extremos de perdas de solo foram distintos quando comparados evento a evento (Figuras 3A e 3B).

Nas Figuras 4A e 4B estão apresentadas as relações entre os dados observados de precipitação e erosão medidos nos eventos que geraram perdas de solo, ocorridos nas Parcelas 1 e 2 . Percebem-se a distribuição de todos os valores de perdas de solo para ambas as parcelas comparando-se com as precipitações observadas. 

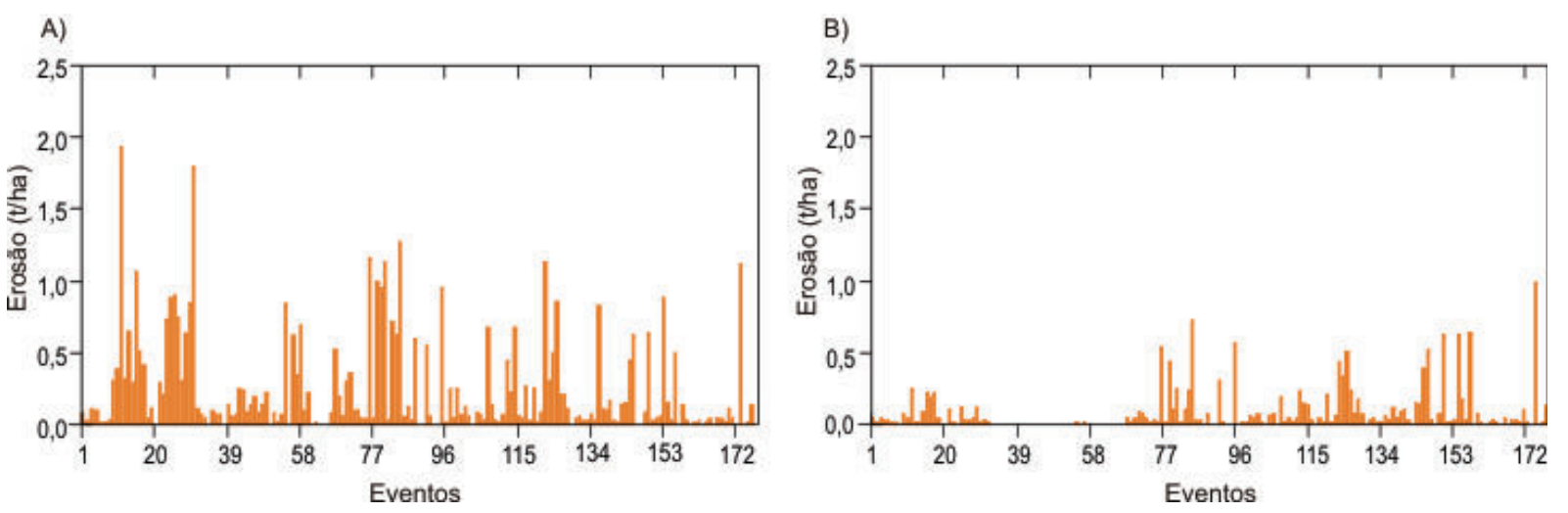

Figura 3 - Erosão nas parcelas de erosão em São João do Cariri: (A) Parcela 1, e (B) Parcela 2.

$\mathrm{Na}$ Parcela 1 (desmatada) os maiores valores registrados foram da ordem de $2 \mathrm{tha}^{-1}$, enquanto na Parcela 2 (com cobertura vegetal) os maiores valores não atingiram $0,8 \mathrm{t} \mathrm{ha}^{-1}$, mostrando assim, a eficácia da caatinga, contra as perdas de solo. A caatinga e sua rugosidade hidráulica impostas ao escoamento superficial são fatores que influenciam na redução exponencial das perdas de solo. Segundo Santos et al. (2009) nas áreas em que ocorre a erosão laminar e a energia de impacto das gotas de chuva é decisiva nos processos de desagregação e transporte de partículas pelo escoamento, os resíduos vegetais na superfície podem reduzir consideravelmente a erosão hídrica.
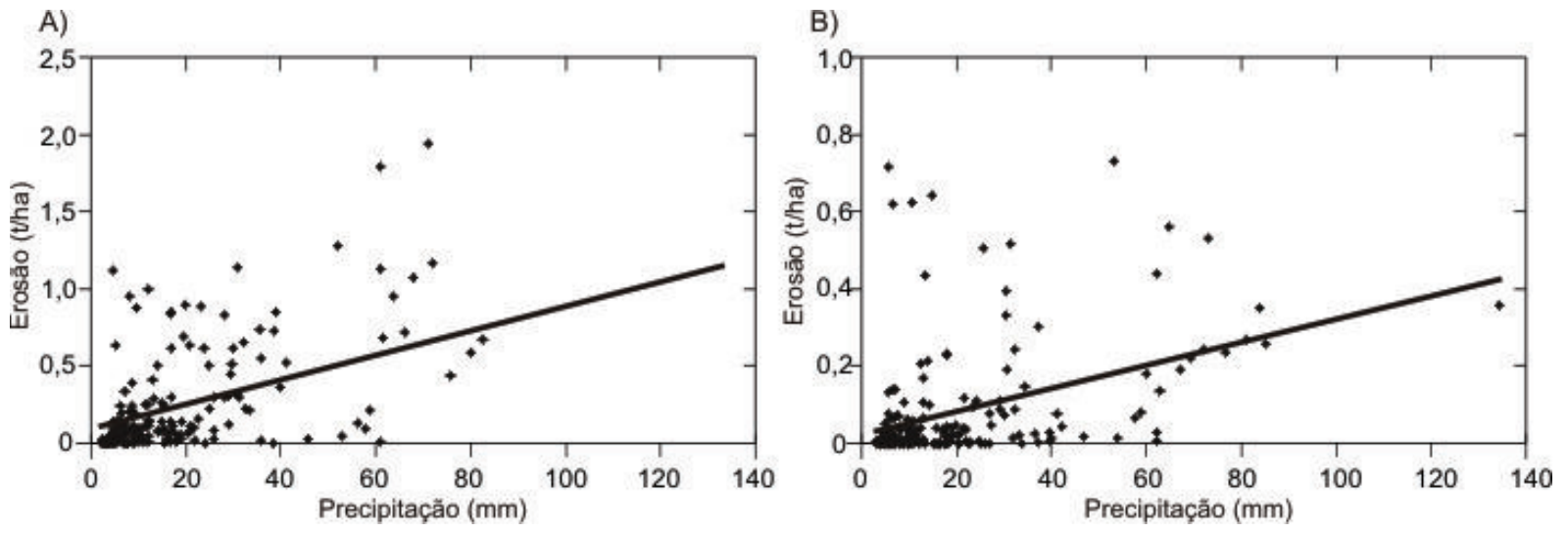

Figura 4 - Relação entre precipitação e erosão nas parcelas de São João do Cariri: (A) Parcela 1, e (B) Parcela 2.

\section{INFLUÊNCIA DA COBERTURA DO SOLO NA ESCALA DE MICROBACIA}

Para analisar a influência direta da cobertura vegetal nos processos hidrossedimentológicos, foram selecionados dois eventos mais representativos, mostrando o comportamento dos hietograma e hidrograma observados e a produção de sedimentos gerados sob chuvas típicas da região semiárida. As características físicas das chuvas determinam sua erosividade, que constitui importante fator nas relações de causa e efeito do processo erosivo dos solos, sendo sua caracterização fundamental para o planejamento conservacionista. As precipitações na região semiárida, como é o caso na BESJC, se caracterizam na maioria dos eventos por concentrarem a maior quantidade de chuva em um pequeno intervalo de tempo, caracterizando desta forma, chuvas bastante erosivas do ponto de vista do impacto das gotas de chuva no solo.

A Figura 5 mostra o hietograma da cheia de 15/02/2002. Observa-se que o evento começou às 18:55, o escoamento superficial iniciou 24 minutos a partir do início da chuva, o pico da vazão ocorreu 19 minutos após o início do escoamento e a maior intensidade ocorreu às 19:12. O evento da cheia de 15/02/2002 produziu um total de sedimentos de $205,96 \mathrm{~kg} \mathrm{ha}^{-1}$. 


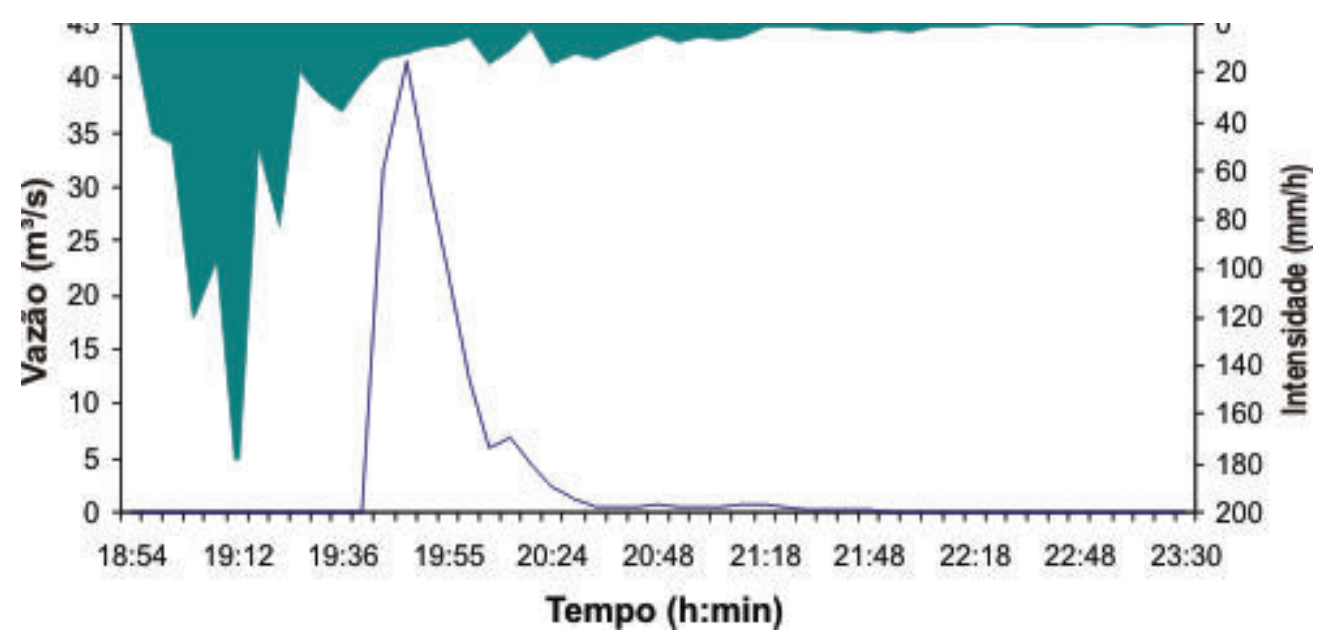

Figura 5 - Hietograma da cheia de 15/02/2002, com hidrograma parcial correspondente na microbacia 1.

A Figura 6 apresenta comportamento semelhante ao hidrograma da Figura 6, mostrando a rápida resposta entre o tempo de empoçamento e o início do escoamento superficial, produzindo um total de sedimentos da ordem de $149,76 \mathrm{~kg} \mathrm{ha}^{-1}$. Deve-se destacar que os solos na região semiárida apresentam características granulométricas e mineralógicas distintas de outros solos existentes no Brasil, o embasamento cristalino e a pequena espessura de solo são condicionantes para que chuvas com pequena duração, mas com significativa intensidade, causem eventos expressivos de produção de sedimentos.

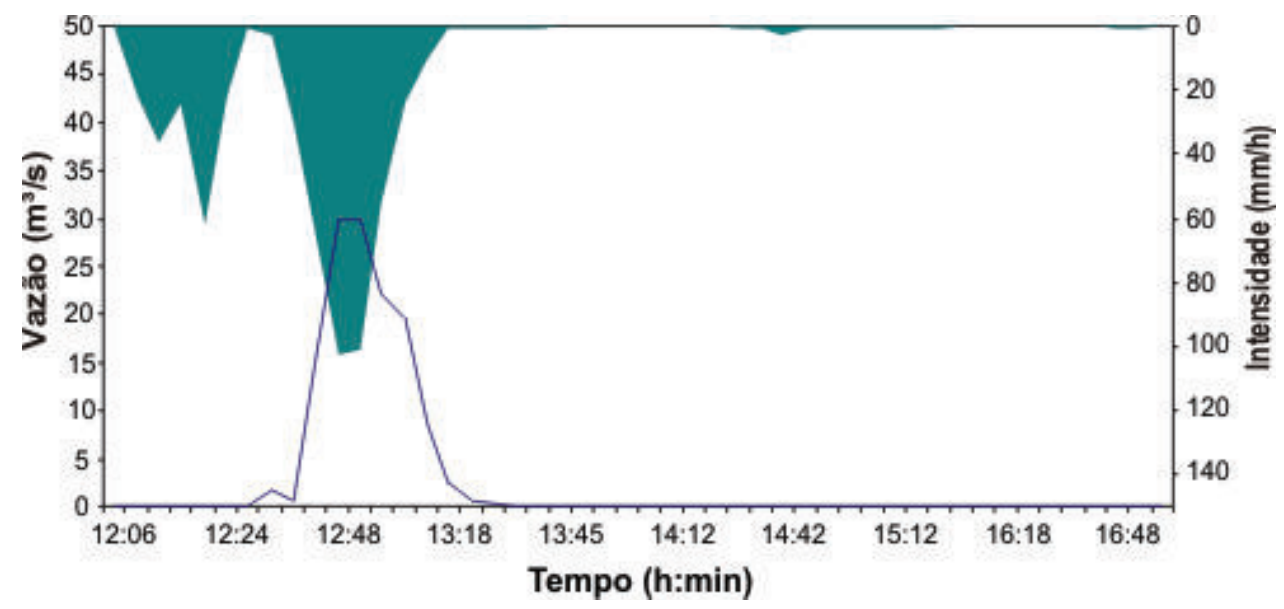

Figura 6 - Hietograma da cheia de 06/03/2002, com hidrograma parcial correspondente na microbacia 1.

Pode-se destacar que, como essa microbacia é mantida desmatada, os processos controladores da erosão são diretamente afetados pelas condições iniciais do solo antes do início do evento chuvoso e pela falta de interceptação da água das chuvas retida nas folhas e galhos. Para Albuquerque et al. (2002), isso também pode ser explicado, provavelmente, pela presença do pavimento desértico, que é uma característica dos solos do tipo Luvissolos, constituídos de calhaus e matacões de quartzo, que servem como agente protetor, interceptando o impacto das gotas de chuva sobre o solo e, por conseguinte, interferindo diretamente no processo de escoamento superficial. De acordo com Albuquerque et al. (2005), esses resultados ressaltam o importante papel que a cobertura vegetal desempenha no controle das perdas de água por escoamento superficial, principalmente quando considerada a irregularidade e a baixa precipitação na região semiárida. 
A Figura 7 mostra as perdas de sedimento e água anuais em função da precipitação média anual na microbacia 1. Verificou-se que em praticamente todos os anos as perdas de água e sedimento tiveram grandezas muito próximas, com exceção para o ano de 2000 , que registrou valores distintos da relação entre perdas de sedimento e água da ordem de 1.139,4 $\mathrm{kg} \mathrm{ha}^{-1}$ e 92,72 mm, respectivamente (Figura 8).

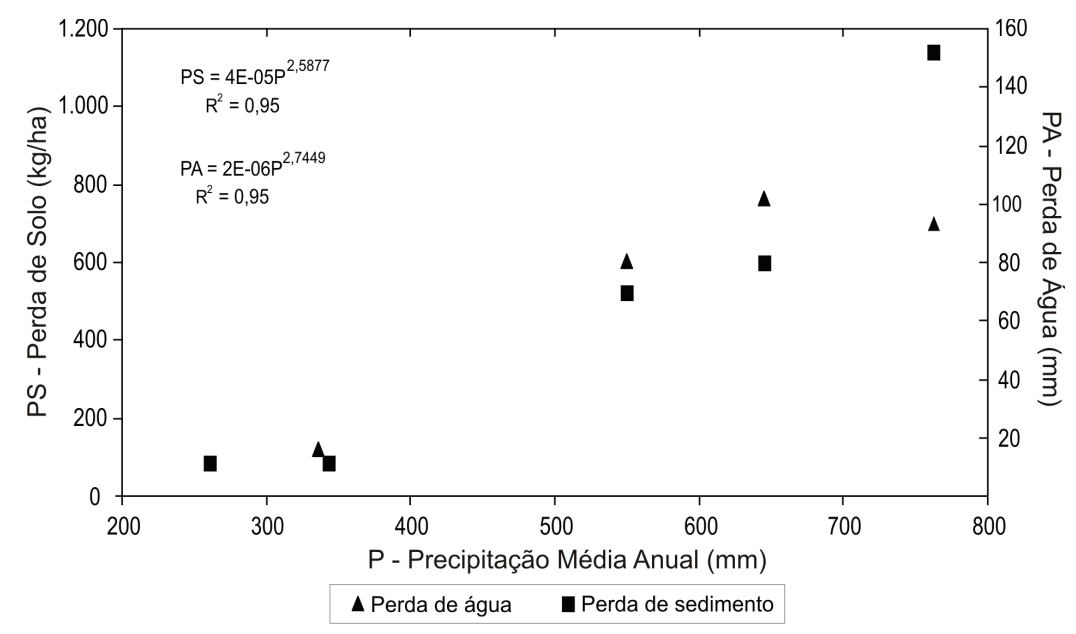

Figura 7 - Perdas de sedimento (PS) e água (PA) anuais em função da precipitação média anual na microbacia 1.

\section{CONSIDERAÇÕES FINAIS}

Este trabalho apresentou os resultados da análise das perdas de água e solo na Bacia Experimental de São João do Cariri, a partir de dados observados de lâmina escoada e erosão, medidos em duas parcelas de $100 \mathrm{~m}^{2}$ com diferentes coberturas superficiais, e em uma microbacia desmatada.

Os resultados de erosão obtidos mostram que a erosão média na Parcela 1 foi 3,4 tha ${ }^{-1}$, enquanto que na Parcela 2 foi de $0,4 \mathrm{t} \mathrm{ha}^{-1}$, mostrando a influência da cobertura vegetal sobre o processo erosivo no semiárido. Sobre os valores observados de lâminas escoadas em São João do Cariri nota-se que a Parcela 1 (desmatada) obteve uma lâmina escoada anual média igual a 173,9 mm, enquanto para a Parcela 2 (mantida um tempo com vegetação rasteira com cobertura morta e outro período desmatada) o valor médio observado foi de $125,5 \mathrm{~mm}$. Com a eliminação da vegetação da superfície os valores nas lâminas escoadas na Parcela 2 aproximaram-se aos valores da Parcela 1.

Os resultados sobre a influência da cobertura vegetal na proteção do solo contra a erosão hídrica comprovaram a importância da preservação da vegetação do tipo caatinga na proteção do solo, garantindo a interceptação das chuvas, diminuição da infiltração e do escoamento superficial.

Os resultados ressaltam o importante papel que a cobertura vegetal pode desempenhar no controle das perdas de sedimento por escoamento superficial, principalmente, quando considerada a irregularidade temporal e espacial das chuvas na região semiárida no Nordeste do Brasil.

\section{AGRADECIMENTOS}

Os autores agradecem ao Laboratório de Recursos Hídricos, da UFCG pela disponibilização dos dados de campo utilizados nesta pesquisa. Os autores são apoiados com recursos e bolsas do CNPq, Finep e MCT/CT-HIDRO.

\section{REFERÊNCIA BIBLIOGRÁFICA}

ALBUQUERQUE, A. W.; MOURA FILHO, G.; SANTOS, J. R.; COSTA, J. P. V.; SOUZA, J. L. Determinação de fatores da Equação Universal de Perda de Solo nas condições de Sumé, PB. Revista Brasileira de Engenharia Agrícola e Ambiental, v.9, p.180-188, 2005. doi: 10.1590/S1415-43662005000200001 
ALBUQUERQUE, A. W.; LOMBARDI NETO, F.; SRINIVASAN, V. S.; SANTOS, J. R. Manejo da cobertura do solo e de práticas conservacionistas nas perdas de solo e água em Sumé, PB. Revista Brasileira de Engenharia Agrícola e Ambiental, v.6, p. 136-141, 2002. doi: 10.1590/S1415-43662002000100024

ALVES, J. J. A.; ARAÚJO, M. A.; NASCIMENTO, S. S. Degradação da caatinga: uma investigação Ecogeográfica. Revista Caatinga, v. 22, n. 3, p 126-135, 2009.

BRANDT, C. J. Transformation of the kinetic energy of rainfall with variable tree canopies. (PhD Thesis in Water Resources) - London University, London, 1986. 446p.

CADIER, E.; FREITAS, B. J.; LEPRUN, J. C. Bacia Experimental de Sumé: instalação e primeiros resultados. Recife: SUDENE. Série Hidrológica, v. 16, 1983. 87p.

CANTALICE, J. R. B.; SILVA, M. D. R. O.; RODRIGUES, J. J. V.; PESSOA, L. M. Estrutura lenhosa e hidrodinâmica do escoamento superficial em uma área de caatinga. Revista Caatinga, v. 21, n. 4, p. 201211, 2008.

FREITAS, F. J.; CANTALICE, J. R. B.; BEZERRA, S. A.; SILVA, M. D. R. O.; SANTOS, P. M.; CORREA, R. M.; LIMA, P. A.; FIGUEIRA, S. B. Erosão em entressulcos sob caatinga e culturas agrícolas. Revista Brasileira de Ciência do Solo, v. 32, p. 1743-1751, 2008. doi: 10.1590/S0100-06832008000400039

GUADAGNIN, J. C.; BERTOL, I.; CASSOL, P. C.; AMARAL, A. J. Perdas de solo, água e nitrogênio por erosão hídrica em diferentes sistemas de manejo. Revista Brasileira de Ciência do Solo, v. 29, p. 277-286, 2005. doi: 10.1590/S0100-06832005000200013

MELO, R. O.; PACHECO, E. P.; MENEZES, J. C.; CANTALICE, J. R. B. Susceptibilidade à compactação e correlação entre as propriedades físicas de um neossolo sob vegetação de caatinga. Revista Caatinga, v. 21, n. 5 (Número Especial), p. 12-17, 2008.

SALES, M. C. L. Evolução dos estudos de desertificação no nordeste brasileiro. GEOUSP - Espaço e Tempo, n. 11, p.115-126, 2002.

SAMPAIO, E. V. S. B.; ARAÚJO, E. L.; SALCEDO, I.; TIESSEN, H. Regeneração da vegetação de caatinga após corte e queima, em Serra Talhada-PE. Pesquisa Agropecuária Brasileira, v. 33, n. 5, p. 621-632, 1998.

SANTOS, C. A. G.; SILVA, R. M.; SRINIVASAN, V. S. Análise das perdas de água e solo em diferentes coberturas superficiais no semi-árido da Paraíba. OKARA: Geografia em debate, v.1, n. 1, p.16-32, 2007.

SANTOS, C. A. G.; SRINIVASAN, V. S.; SILVA, R. M. Evaluation of optimized parameter values of a distributed runoff-erosion model applied in two different basins. IAHS-AISH Publication, v. 292, p. 101109, 2005.

SANTOS, C. A. G.; SRINIVASAN, V. S.; SUZUKI, K.; WATANABE, M. Application of an optimization technique to a physically based erosion model. Hydrological Processes, v. 17, n. 5, p. 989-1003, 2003. doi: 10.1002/hyp. 1176

SANTOS, C. A. G.; SUZUKI, K.; WATANABE, M.; SRINIVASAN, V. S. Influência do tipo da cobertura vegetal sobre a erosão no semi-árido paraibano. Revista Brasileira de Engenharia Agrícola e Ambiental, v. 4, n. 1, p. 92-96, 2000. doi: 10.1590/S1415-43662000000100017

SANTOS, T. E. M.; MONTENEGRO, A. A. A.; PEDROSA, E. M. R. Características hidráulicas e perdas de solo e água sob cultivo do feijoeiro no semi-árido. Revista Brasileira de Engenharia Agrícola e Ambiental, v.13, n. 3, p. 217-225, 2009. doi: 10.1590/S1415-43662009000300001

SILVA, A. B.; RESENDE, M.; SOUSA, A. R.; MARGOLIS, E. Mobilização do solo, erosão e produtividade de milho e feijão em um regossolo no agreste pernambucano. Pesquisa Agropecuária Brasileira, v. 34, n.2, p. 299-307, 1999. doi: 10.1590/S0100-204X1999000200018

SOUZA, B. I.; SUERTEGARAY, D. M. A.; LIMA, E. R. V. Políticas públicas, uso do solo e desertificação nos Cariris Velhos (PB/Brasil). Scripta Nova, v. 14, n. 311, 2010.

SOUZA, B. I.; SUERTEGARAY, D. M. A.; LIMA, E. R. V. Desertificação e seus efeitos na vegetação e solos do Cariri Paraibano. Mercator, v. 8, n. 16, p. 217-232, 2009. doi: 10.4215/RM2009.0816.0017

Trabalho enviado em janeiro de 2011

Trabalho aceito em abril de 2011 